\title{
BET protein inhibition mitigates acute myocardial infarction damage in rats via the TLR4/TRAF6/NF-кB pathway
}

\author{
YANGLI SUN, JIE HUANG and KUNPENG SONG \\ Department of Cardiovascular Internal Medicine, Zhengzhou Central Hospital Affiliated to Zhengzhou University, \\ Zhengzhou, Henan 450007, P.R. China
}

Received November 4, 2014; Accepted September 7, 2015

DOI: $10.3892 /$ etm.2015.2789

\begin{abstract}
Acute myocardial infarction (AMI) is among the most serious cardiovascular diseases and is a leading cause of mortality in developed countries. Previous studies have indicated the central role played by the bromodomain (BRD) proteins, which belong to the BRD and extra-terminal (BET) family, in gene control during heart failure pathogenesis. In addition, BET inhibition has been shown to suppress cardiomyocyte hypertrophy. However, the role of BET proteins in myocardial infarction remains unclear. The present study aimed to investigate whether BETs inhibition mitigates AMI, and explore the molecular mechanism underlying this effect. A rat model of acute myocardial infarction was established, and rats were divided into the sham, AMI and AMI + JQ1 groups. JQ1, a well-known selective BRD inhibitor, was used to suppress BET domain family activity. The mRNA and protein expression levels of BRD2, BRD3 and BRD4 were evaluated using quantitative polymerase chain reaction and western blot analysis, respectively. In addition, the expression levels of markers of cardiac damage were determined using commercial kits. The results indicated that BRD2 and BRD4 mRNA and protein expression levels were significantly increased in the AMI group compared with those in the sham group. In addition, BET inhibition decreased AMI damage in vivo by reversing cardiac function injury, decreasing serum lactate dehydrogenase and creatine kinase-MB isozyme activity, in addition to decreasing the expression levels of high-sensitivity C-reactive protein and interleukin-6. Furthermore, the results suggested that Toll-like receptor 4 (TLR4) signaling was activated by the increased expression of TLR4, TNF receptor-associated
\end{abstract}

Correspondence to: Dr Yangli Sun, Department of Cardiovascular Internal Medicine, Zhengzhou Central Hospital Affiliated to Zhengzhou University, 195 Tongbo Road, Zhengzhou, Henan 450007, P.R. China

E-mail: yanglisun1020@163.com

Key words: acute myocardial infarction, bromodomain and extraterminal family, toll-like receptor 4 , TNF receptor-associated factor 6 , nuclear factor- $\kappa \mathrm{B}$ factor 6 (TRAF6) and nuclear factor (NF)- $\kappa$ B during AMI. However, JQ1 treatment suppressed TLR4 signaling activation. In conclusion, the present results demonstrated that the inhibition of BET family proteins suppresses AMI, and that this effect was partially mediated by the inhibition of TLR4/TRAF6/NF- $\mathrm{B}$ signaling.

\section{Introduction}

Acute myocardial infarction (AMI) is among the most severe cardiovascular diseases and the leading cause of mortality in developed countries (1). The risk of mortality in those who have suffered from non-ST elevation myocardial infarctions is $\sim 10 \%$ in the developed world (2). In addition, $>3$ million people suffer from ST elevation myocardial infarctions and 4 million from non-ST elevation myocardial infarction each year worldwide (3). An intense inflammatory response is a crucial phenomenon in AMI. Increased numbers of inflammatory cells are recruited to the heart following myocardial infarction, which impacts ventricular function and remodeling.

The bromodomain and extra-terminal (BET) family is characterized by one (in plants) or two (in animals/yeast) $\mathrm{N}$-terminal bromodomains (BRDs) and an extra-terminal domain assumed to function as a protein-protein interaction motif. BET proteins associate with chromatin, participating in the modulation of the chromatin structure and influencing transcription $(4,5)$. BET members are implicated in a number of developmental and disease contexts, including spermatogenesis (6), human immunodeficiency virus infection (7), inflammatory diseases (8) and carcinogenesis $(9,10)$. Previous studies have indicated a central role for BET proteins in gene control during heart failure pathogenesis $(11,12)$. JQ1 is a potent BRD selective inhibitor that suppresses BET domain family activity, and is widely used in laboratory research to probe BET function in various diseases $(10,13,14)$. BET inhibition potently suppresses cardiomyocyte hypertrophy in vitro and pathological cardiac remodeling in vivo (15). However, the role of BET proteins in AMI and the underlying mechanism of this involvement remain unclear.

The aim of the present study was to evaluate the potential of BET proteins as signal-responsive regulators of AMI. Furthermore, the study investigated whether Toll-like receptor 4 (TLR4) signaling was involved in the mediation of BET protein function. 


\section{Materials and methods}

AMI rat model. A total of 30 adult Sprague-Dawley rats (age, 8-10 weeks; weight, 250-300 g) were provided by the Shanghai Laboratory Animal Centre (Shanghai, China). This study was approved by the Ethics Committee of Zhengzhou Central Hospital Affiliated to Zhengzhou University (Zhengzhou, China). The investigation was performed in accordance with the Guide for the Care and Use of Laboratory Animals published by the National Institutes of Health (eighth edition; 2011). The rats were randomly divided into three groups, including the sham, AMI and AMI + JQ1 groups ( $\mathrm{n}=8$ per group). The experimental AMI model was induced by the ligation of left coronary artery in adult Sprague-Dawley rats, as previously described (16). Briefly, the rats were anesthetized with $80 \mathrm{mg} / \mathrm{kg}$ ketamine (Eurovet Animal Health B.V., Bladel, Netherlands) and $5 \mathrm{mg} / \mathrm{kg}$ xylazine (Bayer AG, Leverkusen, Germany), intraperitoneally. AMI was induced by occlusion of the left anterior descending coronary artery using a silk suture (Huaiyin Medical Instruments Co., Ltd., Huaian, China). A successful intervention was demonstrated by elevated ST segments on an electrocardiogram (MAC 1600; GE Healthcare, Pittsburgh, PA, USA). The left ventricular end-diastolic dimension (LVEDd), left ventricular end-systolic dimension (LVESd), ejection fraction (EF) and fraction shortening (FS) indices of cardiac function were also measured using an electrocardiogram. In the sham group, rats were exposed to all surgical procedures with the exception of the occlusion of the anterior descending coronary artery. JQ1 was synthesized by Selleck Chemicals (Houston, TX, USA). Rats in the AMI + JQ1 group were intraperitoneally injected with $50 \mathrm{mg} / \mathrm{kg} \mathrm{JQ} 1$ at $12 \mathrm{~h}$ prior to and $12 \mathrm{~h}$ after AMI. At $24 \mathrm{~h}$ following the surgical intervention, the rats were sacrificed by an intraperitoneal injection of pentobarbital $(200 \mathrm{mg} / \mathrm{kg}$; Sigma-Aldrich, St. Louis, MO, USA). Blood samples ( $\sim 6 \mathrm{ml})$ were collected from the common carotid artery and stored at $-20^{\circ} \mathrm{C}$, and the rat hearts were excised and stored at $-80^{\circ} \mathrm{C}$.

Reverse transcription-quantitative polymerase chain reaction $(R T-q P C R)$. Total RNA was isolated from the rat myocardial tissues using TRIzol reagent (Invitrogen; Thermo Fisher Scientific, Inc., Carlsbad, CA, USA). Next, $2 \mu \mathrm{g}$ total RNA was reverse transcribed into cDNA using a RevertAid ${ }^{\mathrm{TM}}$ First Strand cDNA Synthesis kit (Fermentas; Thermo Fisher Scientific, Vilnius, Lithuania) according to the manufacturer's instructions. qPCR was performed in an Applied Biosystems Prism 7300 Sequence Detection system (Thermo Fisher Scientific, Inc., Foster City, CA, USA) using a SYBR Green PCR kit (Applied Biosystems; Thermo Fisher Scientific, Inc.). Briefly, the PCR reaction mix (final volume, $25 \mu \mathrm{l}$ ) consisted of: $1 \mu \mathrm{l}$ cDNA, $100 \mathrm{nM}$ primers and $12.5 \mu \mathrm{l}$ 2X SYBR Green PCR Master Mix. The PCR cycling conditions were as follows: Initial denaturation at $94^{\circ} \mathrm{C}$ for $3 \mathrm{~min}$, followed by 40 cycles of denaturation at $94^{\circ} \mathrm{C}$ for $30 \mathrm{sec}$, annealing at $60^{\circ} \mathrm{C}$ for $30 \mathrm{sec}$ and elongation at $72^{\circ} \mathrm{C}$ for $45 \mathrm{sec}$, and a final elongation step at $72^{\circ} \mathrm{C}$ for $5 \mathrm{~min}$. The primers were as follows: BRD2, forward 5'-AGCACTGTCAAGCGGAAGAT-3', reverse 5'-GGCAAG GCAGTAGAGACAGG-3'; BRD3, forward 5'-AAGATG GTGAGGTCCCACAG-3', reverse 5'-GGTACTCACGGC TGTCCATT-3'; BDR4, forward 5'-ACAGCCCCAACAGAA CAAAC-3', reverse 5'-GCTGGTTCCTTCTTGCTCAC-3'; and
Table I. Indices of cardiac function in the three groups.

\begin{tabular}{lccc}
\hline Parameter & Sham & AMI & AMI + JQ1 \\
\hline LVEDd (mm) & $5.62 \pm 0.09$ & $9.38 \pm 0.14^{\mathrm{a}}$ & $6.22 \pm 0.11^{\mathrm{b}}$ \\
LVESd (mm) & $2.21 \pm 0.04$ & $7.61 \pm 0.11^{\mathrm{a}}$ & $4.15 \pm 0.06^{\mathrm{b}}$ \\
EF $(\%)$ & $75.1 \pm 6.2$ & $34.2 \pm 2.1^{\mathrm{a}}$ & $48.3 \pm 4.9^{\mathrm{b}}$ \\
FS $(\%)$ & $45.2 \pm 3.6$ & $14.2 \pm 1.1^{\mathrm{a}}$ & $36.3 \pm 2.8^{\mathrm{b}}$ \\
\hline
\end{tabular}

${ }^{\mathrm{a}} \mathrm{P}<0.05$ vs. sham group; ${ }^{\mathrm{b}} \mathrm{P}<0.05$ vs. AMI group. AMI, acute myocardial infarction; LVEDd, left ventricular end-diastolic dimension; LVESd, left ventricular end-systolic dimension; EF, ejection fraction; FS, fraction shortening.

glyceraldehyde 3-phosphate dehydrogenase (GAPDH), forward 5'-CTCATGACCACAGTCCATGC-3' and reverse 5'-TTCAGC TCTGGGATGACCTT-3' (Sangon Biotech Co., Ltd., Shanghai, China). The relative quantities of each mRNA were calculated using the $2^{-\Delta \Delta \mathrm{Ct}}$ method (SDS Software version 1.4.1; Applied Biosystems; Thermo Fisher Scientific, Inc.) with GAPDH as an internal control.

Western blot analysis. Total protein was lysed from tissues using ice-cold lysis buffer containing $50 \mathrm{mM}$ Tris- $\mathrm{HCl}(\mathrm{pH} 7.5$; Amresco LLC, Solon, OH, USA), $150 \mathrm{mM} \mathrm{NaCl}$ (Dingshengxin Company, Tianjin, China), $1 \%$ Nonidet P-40 (Amresco LLC), $1 \mathrm{mM}$ sodium orthovanadate (Beyotime Institute of Biotechnology, Shanghai, China), $1 \mathrm{mM}$ dithiothreitol (Amresco LLC), $0.2 \%$ SDS (Sigma-Aldrich) and $1 \mathrm{mM}$ phenylmethylsulfonyl fluoride (Beyotime Institute of Biotechnology). Following centrifugation at $13,000 \mathrm{x} \mathrm{g}$ for $1 \mathrm{~min}$, protein concentrations were detected using a Bicinchoninic Protein Assay kit (Beyotime Institute of Biotechnology). Subsequently, the protein samples were separated on a $12 \%$ SDS-polyacrylamide gel via electrophoresis and transferred to polyvinylidene difluoride membranes (EMD Millipore, Billerica, MA, USA). The membranes were incubated in blocking solution (Tris-buffered saline containing $5 \%$ nonfat milk and $0.05 \%$ Tween 20 ) at $4^{\circ} \mathrm{C}$ overnight. The blot was then probed with the following primary antibodies: Polyclonal rabbit anti-TLR4 (1:500; cat. no. sc-30002), polyclonal goat anti-TNF receptor-associated factor 6 (TRAF6; 1:400; cat. no. sc-33897), monoclonal mouse anti-nuclear factor (NF)-кB (1:800; cat. no. sc-8008) (Santa Cruz Biotechnology, Inc., Santa Cruz, CA, USA), polyclonal goat anti-BRD2 (1:400; cat. no. ab3718), polyclonal rabbit anti-BRD3 (1:200; cat. no. ab83478) and polyclonal rabbit anti-BRD4 (1:400; cat. no. ab75898) (Abcam, Cambridge, MA, USA) at $37^{\circ} \mathrm{C}$ for $2 \mathrm{~h}$. Subsequently, the membranes were incubated with horseradish peroxidase-conjugated secondary antibodies: Goat anti-rabbit immunoglobulin (Ig)G (1:10,000; cat. no. sc-2004), rabbit anti-goat $\operatorname{IgG}(1: 10,000$; cat. no. sc-2768) and goat anti-mouse IgG (1:10,000; cat. no. sc-2031) (Santa Cruz Biotechnology, Inc.) at $37^{\circ} \mathrm{C}$ for $1 \mathrm{~h}$. The signal was detected using an enhanced chemiluminescence western blotting kit (Pierce Biotechnology, Inc., Rockford, IL, USA). The intensity of the bands was quantified using a ScanJet 4C Flatbed Scanner (Hewlett-Packard, Palo Alto, CA, USA) with National Institutes of Health Image v1.52 software (http://rsb.info.nih.gov/nih-image). 
A
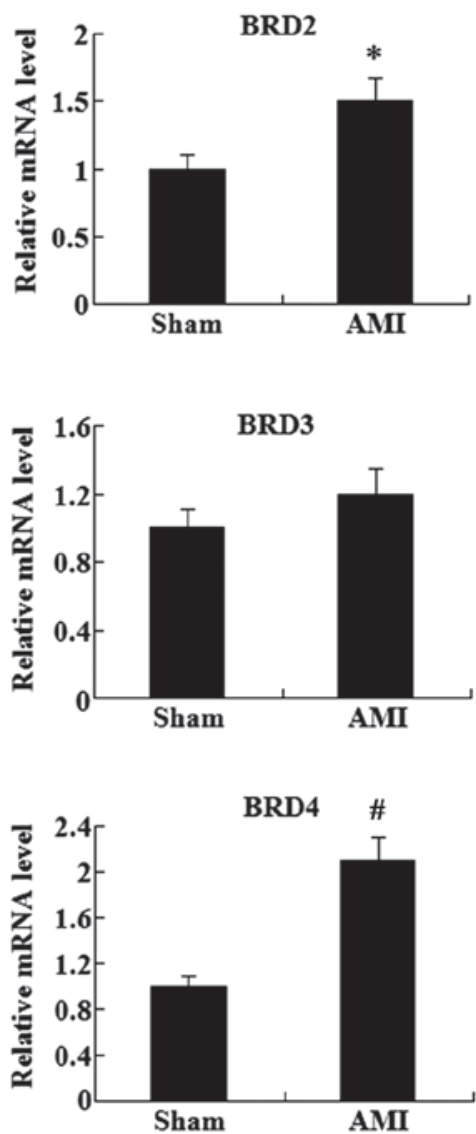
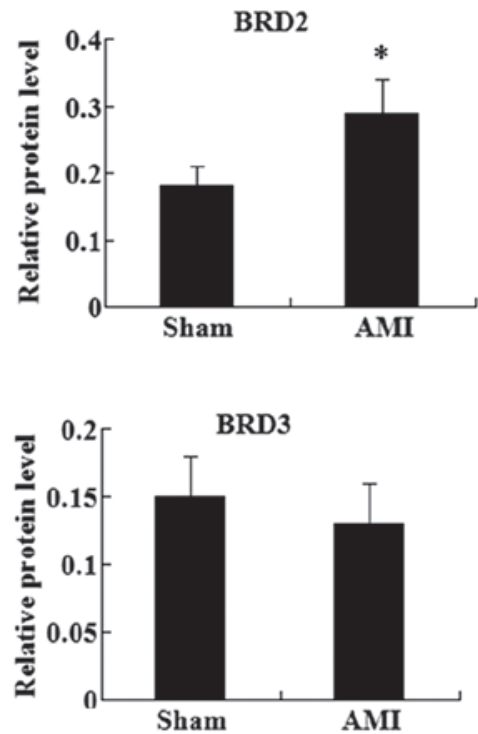

BRD4
$\mathbf{C}$
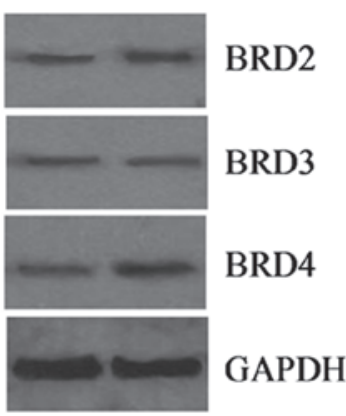

12

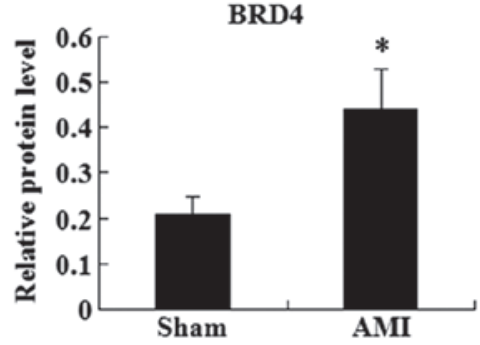

Figure 1. Expression of the BET domain family in the cardiomyocytes of rats with AMI. Relative (A) mRNA and (B) protein expression levels of BRD2, BRD3 and BRD4 in the myocardial tissues. (C) Western blot, showing the protein expression in the sham (lane 1) and AMI (lane 2) groups. ${ }^{*} \mathrm{P}<0.05$ and ${ }^{~} \mathrm{P}<0.01$ vs. sham group. BET, bromodomain and extra-terminal; AMI, acute myocardial infarction; BRD, bromodomain; GAPDH, glyceraldehyde 3-phosphate dehydrogenase.
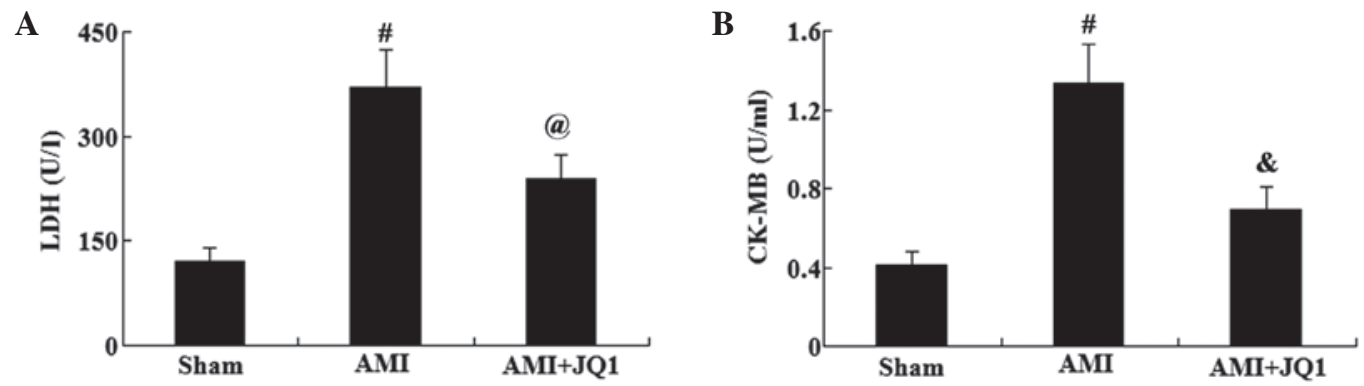

Figure 2. Effect of BET domain family inhibition on AMI damage in cardiomyocytes. (A) LDH and (B) CK-MB activity in the serum. ${ }^{\# P}<0.01$ vs. sham group; ${ }^{\complement} \mathrm{P}<0.05$ and ${ }^{\circledR} \mathrm{P}<0.01$ vs. AMI group. BET, bromodomain and extra-terminal; AMI, acute myocardial infarction; LDH, lactate dehydrogenase; $\mathrm{CK}-\mathrm{MB}$, creatine kinase MB isoenzyme.

Lactate dehydrogenase $(\mathrm{LDH})$ and creatine kinase-MB $(C K-M B)$ isozyme measurement. Blood samples were centrifuged at $1,500 \mathrm{x}$ for $15 \mathrm{~min}$ at $4^{\circ} \mathrm{C}$, and then the serum was separated and stored at $-80^{\circ} \mathrm{C}$ until analyzed. An LDH assay kit was purchased from Jiancheng Bioengineering Institute (Nanjing, China) and a CK-MB isozyme assay kit was obtained from Ningbo Medical System Biotechnology Co., Ltd. (Ningbo, China). LDH and CK-MB activities in the serum were determined according to the manufacturer's instructions.

High-sensitivity $C$-reactive protein (hs-CRP) and interleukin (IL)-6 measurement. An hs-CRP assay kit was purchased from
Shanghai ExCell Biology, Inc. (Shanghai, China) and the serum hs-CRP concentration was quantified using a Cobas Integra 400 Plus ${ }^{\circledR}$ Automatic Chemistry analyzer (Roche Diagnostics, Basel, Switzerland) using an immunoturbidimetric method. The IL-6 levels in the myocardial tissue were determined using enzyme-linked immunosorbent assay kits obtained from eBioscience, Inc. (San Diego, CA, USA), following the manufacturer's instructions.

Statistical analysis. The results were analyzed using SPSS statistical software, version 19.0 (IBM SPSS, Armonk, NY, USA) and all the data are expressed as the mean \pm standard 
A

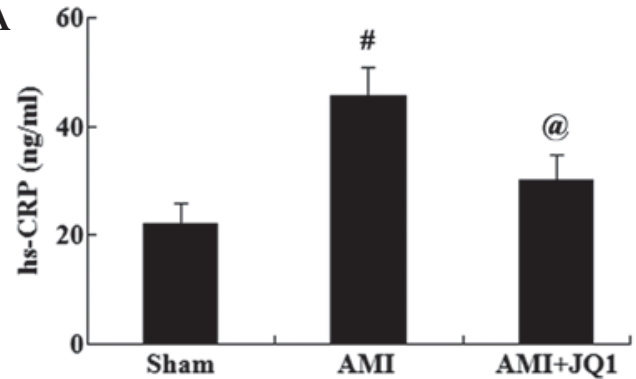

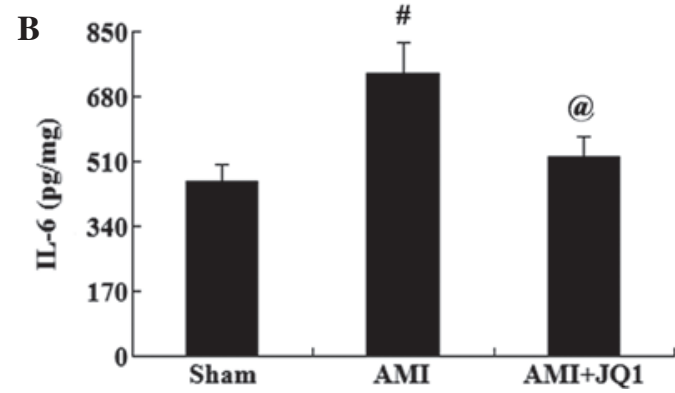

Figure 3. Effect of BET domain family inhibition on inflammatory reactions in cardiomyocytes. Expression levels of (A) hs-CRP in serum and (B) IL-6 in myocardial tissue. ${ }^{\#} \mathrm{P}<0.01$ vs. sham group; ${ }^{\circledR} \mathrm{P}<0.05$ vs. AMI group. BET, bromodomain and extra-terminal; AMI, acute myocardial infarction; hs-CRP, high-sensitivity C-reactive protein; IL-6, interleukin-6.

A

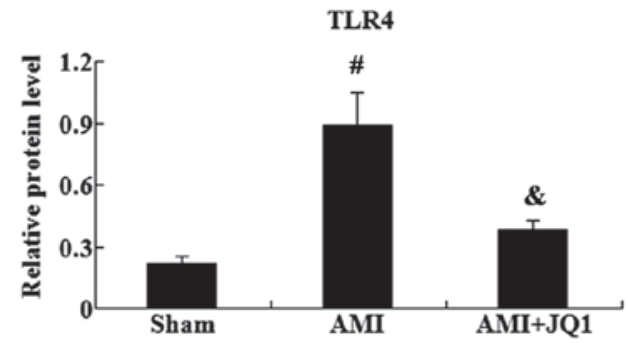

C

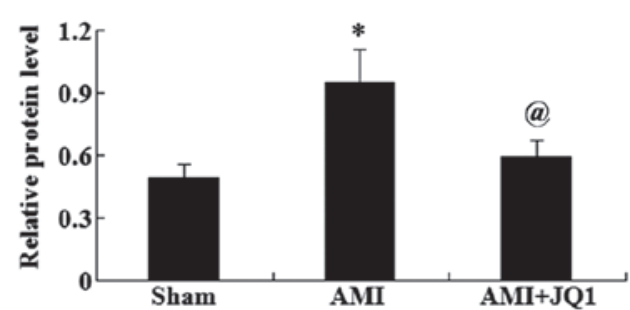

B

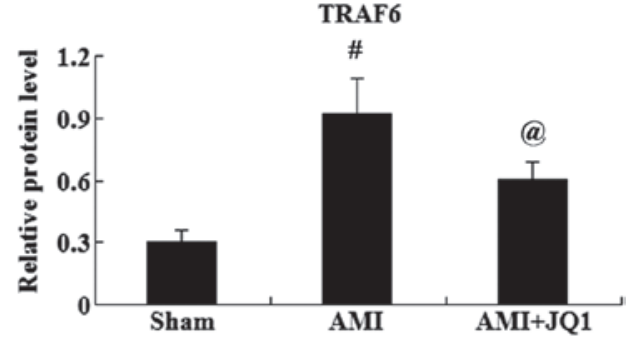

D

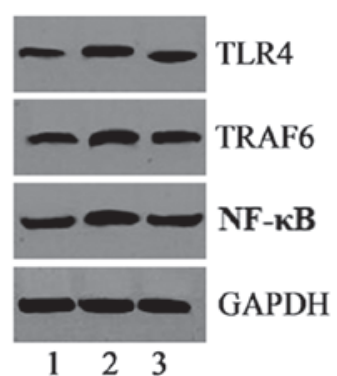

Figure 4. Effect of BET domain family inhibition on the expression of TLR4/TRAF6/NF- $\mathrm{kB}$ in cardiomyocytes. Relative protein expression levels of (A) TLR4, (B) TRAF6 and (C) NF-kB in cardiomyocytes in the sham, AMI and AMI + JQ1 groups are shown. (D) Western blot, showing the protein expression in the sham (lane 1), AMI (lane 2) and AMI + JQ1 groups. "P $<0.05$ and ${ }^{\prime \prime} \mathrm{P}<0.01$ vs. sham group; ${ }^{\circledR} \mathrm{P}<0.05$ and ${ }^{\&} \mathrm{P}<0.01$ vs. AMI group. BET, bromodomain and

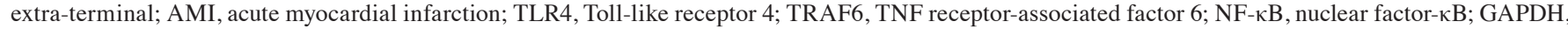
glyceraldehyde 3-phosphate dehydrogenase.

deviation. Student's t-test was used for comparison of differences between the groups. $\mathrm{P}<0.05$ was considered to indicate a statistically significant difference.

\section{Results}

Effect of BET domain family inhibition on cardiac function in the cardiomyocytes. Following the establishment of the AMI model, it was observed that the LVEDd and LVESd were significantly increased, while the EF and FS were significantly decreased. Subsequently, JQ1, a well-known selective BRD inhibitor, was used to investigate the effect of BET inhibition on cardiac function in the established AMI model. The results indicated that LVEDd and LVESd were significantly decreased, while EF and FS were significantly increased, in the AMI + JQ1 group compared with the AMI group $(\mathrm{P}<0.05$; Table I).

Expression of BET domain family in the cardiomyocytes. To detect the expression of BETs in the myocardial tissue,
RT-qPCR and western blot analysis were used to determine the mRNA and protein expression levels, respectively, of BRD2, BRD3 and BRD4. The results showed that the mRNA and protein expression levels of BRD2, BRD3 and BRD4 were detectable in the myocardial tissue (Fig. 1). Compared with the sham group, the mRNA and protein expression levels of BRD2 and BRD4 were significantly increased in the AMI group. However, BRD3 expression was not found to be significantly different in the AMI group compared with that in the sham group ( $\mathrm{P}>0.05$; Fig. 1$)$.

Effect of BET domain family inhibition on $L D H$ and $C K-M B$ activity in the cardiomyocytes. The myocardial enzymes, $\mathrm{LDH}$ and CK-MB, are indicators of myocardial damage following AMI. Serum activities of LDH and CK-MB were evaluated using commercially available kits (Fig. 2). Compared with the sham group, the serum activities of LDH and CK-MB were significantly elevated in the AMI group $(\mathrm{P}<0.01)$. However, JQ1 treatment was found to significantly reduce the serum activities of LDH $(\mathrm{P}<0.05)$ and $\mathrm{CK}-\mathrm{MB}(\mathrm{P}<0.01)$ in rats with AMI. 
Effect of BET domain family inhibition on inflammatory reaction in the cardiomyocytes. To assess the effect of BETs inhibition on the inflammatory response, the levels of hs-CRP and IL-6 were determined using commercially available kits. As shown in Fig. 3, the levels of hs-CRP in the serum and of IL-6 in the myocardial tissue were significantly increased in the AMI group compared with those in the sham group $(\mathrm{P}<0.01)$. However, the levels of hs-CRP and IL-6 were significantly decreased in the AMI + JQ1 group compared with those in the AMI group $(\mathrm{P}<0.05)$.

Effect of BET domain family inhibition on the protein expression levels of TLR4/TRAF6/NF- $K B$ in rats with AMI. Western blot analysis was used to determine the association between the BET domain family and the expression of TLR4/TRAF6/NF- $\kappa$ B in the cardiomyocytes of rats with AMI. As shown in Fig. 4, the protein expression levels of TLR4, TRAF6 and NF- $\kappa \mathrm{B}(\mathrm{P}<0.01$, $\mathrm{P}<0.01$ and $\mathrm{P}<0.05$, respectively) were significantly increased in the AMI group compared with those in the sham group. By contrast, the administration of JQ1 significantly reduced the protein expression levels of TLR4, TRAF6 and NF- $\mathrm{BB}(\mathrm{P}<0.01$, $\mathrm{P}<0.05$ and $\mathrm{P}<0.05$, respectively) in rats with $\mathrm{AMI}$.

\section{Discussion}

The acetylation of $\mathrm{N}$-terminal histone tails serves a crucial function in gene regulation (17). Members of the BET family of bromodomain (BRD)-containing reader proteins, including BRD2, BRD3, BRD4 and testis-specific BRDT, bind to acetylated lysine residues on histone and nonhistone proteins, and recruit transcriptional regulators, leading to the activation or repression of gene transcription (18-20). In the present study, RT-qPCR and western blot analysis were performed to determine the mRNA and protein expression levels, respectively, of the BET family members BRD2, BRD3 and BRD4 in rat myocardial tissue. The results demonstrated that the mRNA and protein expression levels of BRD2, BRD3 and BRD4 were detectable in the myocardial tissue. Furthermore, a rat model of AMI was established, and the results showed that BRD2 and BRD4 expression was significantly increased in the AMI group compared with the sham group. However, BRD3 expression was not altered between the AMI and sham groups. These results indicated that BRD2 and BRD4 proteins were associated with AMI, whereas BRD3 may not be associated with AMI.

JQ1 is a well-known selective BRD inhibitor that competes with members of the BET family of BRDs by displacing BET BRDs from chromatin and resulting in the suppression of downstream signaling events to RNA polymerase II (Pol II) $(9,10,21)$. Hence, JQ1 was utilized to probe BET function in a rat cardiomyocyte model of AMI.

Myocardial infarction is the primary cause of the development of congestive heart failure in the left ventricle. CK-MB and LDH are sensitive biochemical indicators of myocardial injury. AMI leads to cardiomyocyte death, which in turn results in the coordinated activation of a cytokine cascade that initiates an acute inflammatory reaction (22). hs-CRP is considered to be a sensitive indicator of inflammation that is associated with AMI, as increased serum hs-CRP levels have been detected in post-infarction patients (23). Increased levels of hs-CRP indicate a poor prognosis in patients following an AMI (24). A previous study indicated that the serum IL-6 concentrations of the AMI group were significantly higher compared with the control group (25). JQ1 is a selective BRD inhibitor. In the present study, a model of AMI was established in rats, and it was observed that treatment with JQ1 reversed cardiac function injury, decreased serum LDH and CK-MB activities, and decreased the expression levels of hs-CRP and IL-6. These findings suggested that BET inhibition may potently suppress myocardial infarction in vivo.

Toll-like receptors (TLRs) are germline-encoded pattern recognition receptors that are involved in the initiation of innate immune responses (26-28). TLR4 is a key member of the TLR family that may be activated by lipopolysaccharide and nonbacterial agonists $(29,30)$. Furthermore, TLR4 is localized on the cell surface and mediates transmembrane signaling transduction. Previous studies demonstrated that AMI is accompanied by the activation of TLR4 in circulating blood cells $(31,32)$. In animal models, TLR4 deficiency or signaling inhibition have been shown to reduce inflammatory cell influx into the infarcted area, ameliorate cardiac remodeling and decrease infarct size (33-35). In addition, TLR pathway activation was indicated by increased expression of TLR4 in patients with acute ST elevation myocardial infarction (36). The activation of TLR4 signaling leads to the synthesis and release of cytokines and inflammatory mediators. For instance, the nuclear factor (NF)- $\kappa \mathrm{B}$ pathway has been suggested to serve a crucial function in TLR4-mediated inflammatory regulation (37). In myocardial infarction models, $N F-\kappa B$ activation has been associated with the remodeling and dysfunction of the myocardium (38). TNF receptor-associated factor 6 (TRAF6) may be activated by TLR4, which in turn activates the inhibitor of $\kappa \mathrm{B}$ kinase, leading to the activation of $\mathrm{NF}-\kappa \mathrm{B}$ (39). In the present study, the involvement of the TLR4/TRAF6/NF- $\kappa$ B pathway in the effect of BET proteins on AMI was investigated. The results suggested that TLR4 signaling was activated by the increased expression of TLR4, TRAF6 and NF- $\mathrm{B}$ in the cardiomyocytes of rats that underwent AMI. However, JQ1 treatment suppressed this TLR4 signaling activation. These results indicate that the regulation of TLR4/TRAF6/NF- $\kappa \mathrm{B}$ signaling by BET family members may underlie the effect of BET proteins on gene expression following AMI.

In conclusion, the present study demonstrated that the inhibition of BET family proteins suppresses certain manifestations of AMI, and that this effect was partially mediated by the inhibition of the TLR4/TRAF6/NF- $\kappa$ B pathway. These results suggest that BET proteins may be associated with the pathogenesis of AMI, and may be a novel target for the treatment of AMI.

\section{References}

1. Ozaki K, Sato H, Inoue K, Tsunoda T, Sakata Y, Mizuno H, Lin TH, Miyamoto Y, Aoki A, Onouchi Y, et al: SNPs in BRAP associated with risk of myocardial infarction in Asian populations. Nat Genet 41: 329-333, 2009.

2. Task Force on the management of ST-segment elevation acute myocardial infarction of the European Society of Cardiology (ESC); Steg PG, James SK, Atar D, Badano LP, Blömstrom-Lundqvist C, Borger MA, Di Mario C, Dickstein K, Ducrocq G, Fernandez-Aviles F, et al: ESC Guidelines for the management of acute myocardial infarction in patients presenting with ST-segment elevation. Eur Heart J 33: 2569-2619, 2012. 
3. White HD and Chew DP: Acute myocardial infarction. Lancet 372: 570-584, 2008.

4. Florence B and Faller DV: You bet-cha: A novel family of transcriptional regulators. Front Biosci 6: D1008-D1018, 2001.

5. Florence BL and Faller DV: Drosophila female sterile (1) homeotic is a multifunctional transcriptional regulator that is modulated by Ras signaling. Dev Dyn 237: 554-564, 2008.

6. Matzuk MM, McKeown MR, Filippakopoulos P, Li Q Ma L, Agno JE, Lemieux ME, Picaud S, Yu RN, Qi J, et al: Small-molecule inhibition of BRDT for male contraception. Cell 150: 673-684, 2012.

7. Banerjee C, Archin N, Michaels D, Belkina AC, Denis GV, Bradner J, Sebastiani P, Margolis DM and Montano M: BET bromodomain inhibition as a novel strategy for reactivation of HIV-1. J Leukoc Biol 92: 1147-1154, 2012.

8. Nicodeme E, Jeffrey KL, Schaefer U, Beinke S, Dewell S, Chung CW, Chandwani R, Marazzi I, Wilson P, Coste H, et al: Suppression of inflammation by a synthetic histone mimic. Nature 468: 1119-1123, 2010.

9. Delmore JE, Issa GC, Lemieux ME, Rahl PB, Shi J, Jacobs HM, Kastritis E, Gilpatrick T, Paranal RM, Qi J, et al: BET bromodomain inhibition as a therapeutic strategy to target c-Myc. Cell 146: 904-917, 2011.

10. Filippakopoulos P, Qi J, Picaud S, Shen Y, Smith WB, Fedorov O, Morse EM, Keates T, Hickman TT, Felletar I, et al: Selective inhibition of BET bromodomains. Nature 468: 1067-1073, 2010.

11. Anand P, Brown JD, Lin CY, Qi J,Zhang R, Artero PC, Alaiti MA, Bullard J, Alazem K, Margulies KB, et al: BET bromodomains mediate transcriptional pause release in heart failure. Cell 154: 569-582, 2013.

12. Haldar SM and McKinsey TA: BET-ting on chromatin-based therapeutics for heart failure. J Mol Cell Cardiol 74: 98-102, 2014

13. Delmore JE, Issa GC, Lemieux ME, Rahl PB, Shi J, Jacobs HM, Kastritis E, Gilpatrick T, Paranal RM, Qi J, et al: BET bromodomain inhibition as a therapeutic strategy to target c-Myc. Cell 146: 904-917, 2011.

14. Tang X, Peng R, Ren Y, Apparsundaram S, Deguzman J, Bauer CM, Hoffman AE, Hamilton S, Liang Z, Zeng H, et al: BET bromodomain proteins mediate downstream signaling events following growth factor stimulation in human lung fibroblasts and are involved in bleomycin-induced pulmonary fibrosis. Mol Pharmacol 83 283-293, 2013.

15. Spiltoir J, Stratton MS, Cavasin MA, Demos-Davies K, Reid BG, Qi J, Bradner JE and McKinsey TA: BET acetyl-lysine binding proteins control pathological cardiac hypertrophy. J Mol Cell Cardiol 63: 175-179, 2013.

16. Eckle T, Grenz A, Köhler D, Redel A, Falk M, Rolauffs B, Osswald H, Kehl F and Eltzschig HK: Systematic evaluation of a novel model for cardiac ischemic preconditioning in mice. Am J Physiol Heart Circ Physiol 291: H2533-H2540, 2006.

17. Marushige K: Activation of chromatin by acetylation of histone side chains. Proc Natl Acad Sci USA 73: 3937-3941, 1976.

18. Dhalluin C, Carlson JE, Zeng L, He C, Aggarwal AK and Zhou MM: Structure and ligand of a histone acetyltransferase bromodomain. Nature 399: 491-496, 1999.

19. Jacobson RH, Ladurner AG, King DS and Tjian R: Structure and function of a human TAFII250 double bromodomain module. Science 288: 1422-1425, 2000

20. Owen DJ, Ornaghi P, Yang JC, Lowe N, Evans PR, Ballario P, Neuhaus D, Filetici P and Travers AA: The structural basis for the recognition of acetylated histone $\mathrm{H} 4$ by the bromodomain of histone acetyltransferase gen5p. EMBO J 19: 6141-6149, 2000.

21. Chung CW, Coste H, White JH, Mirguet O, Wilde J, Gosmini RL, Delves C, Magny SM, Woodward R, Hughes SA, et al: Discovery and characterization of small molecule inhibitors of the BET family bromodomains. J Med Chem 54: 3827-3838, 2011.

22. Frangogiannis NG, Smith CW and Entman ML: The inflammatory response in myocardial infarction. Cardiovasc Res 53: 31-47, 2002.
23. Freitas F, Brucker N, Durgante J, Bubols G, Bulcão R, Moro A, Charão M, Baierle M, Nascimento S, Gauer B, et al: Urinary 1-hydroxypyrene is associated with oxidative stress and inflammatory biomarkers in acute myocardial infarction. Int J Environ Res Public Health 11: 9024-9037, 2014.

24. Kang YU, Kim MJ, Choi JS, Kim CS, Bae EH, Ma SK, Ahn YK, Jeong MH, Kim YJ, Cho MC, et al; Other Korea Acute Myocardial Infarction Registry Investigators: Concomitant impact of high-sensitivity $\mathrm{C}$-reactive protein and renal dysfunction in patients with acute myocardial infarction. Yonsei Med J 55: 132-140, 2014.

25. Wang XH, Liu SQ, Wang YL and Jin Y: Correlation of serum high-sensitivity C-reactive protein and interleukin-6 in patients with acute coronary syndrome. Genet Mol Res 13: 4260-4266, 2014

26. Takeda K, Kaisho T and Akira S: Toll-like receptors. Annu Rev Immunol 21: 335-376, 2003.

27. Beutler B: Inferences, questions and possibilities in Toll-like receptor signalling. Nature 430: 257-263, 2004.

28. Akira S, Uematsu S and Takeuchi O: Pathogen recognition and innate immunity. Cell 124: 783-801, 2006.

29. Poltorak A, He X, Smirnova I, Liu MY, Van Huffel C, Du X, Birdwell D, Alejos E, Silva M, Galanos C, et al: Defective LPS signaling in $\mathrm{C} 3 \mathrm{H} / \mathrm{HeJ}$ and $\mathrm{C} 57 \mathrm{BL} / 10 \mathrm{ScCr}$ mice: Mutations in Tlr4 gene. Science 282: 2085-2088, 1998.

30. Lee JY, Ye J, Gao Z, Liu MY, Van Huffel C, Du X, Birdwell D, Alejos E, Silva M and Galanos C: Reciprocal modulation of Toll-like receptor-4 signaling pathways involving MyD88 and phosphatidylinositol 3-kinase/AKT by saturated and polyunsaturated fatty acids. J Biol Chem 278: 37041-37051, 2003.

31. Arslan F, de Kleijn DP and Pasterkamp G: Innate immune signaling in cardiac ischemia. Nat Rev Cardiol 8: 292-300, 2011.

32. Timmers L, Pasterkamp G, de Hoog VC, Arslan F, Appelman Y and de Kleijn DP: The innate immune response in reperfused myocardium. Cardiovasc Res 94: 276-283, 2012.

33. Chong AJ, Shimamoto A, Hampton CR, Takayama $H$, Spring DJ, Rothnie CL, Yada M, Pohlman TH and Verrier ED: Toll-like receptor 4 mediates ischemia/reperfusion injury of the heart. J Thorac Cardiovasc Surg 128: 170-179, 2004.

34. Timmers L, Sluijter JP, van Keulen JK, Hoefer IE, Nederhoff MG, Goumans MJ, Doevendans PA, van Echteld CJ, Joles JA, Quax PH, et al: Toll-like receptor 4 mediates maladaptive left ventricular remodeling and impairs cardiac function after myocardial infarction. Circ Res 102: 257-264, 2008

35. Shimamoto A, Chong AJ, Yada M, Shomura S, Takayama H, Fleisig AJ, Agnew ML, Hampton CR, Rothnie CL, Spring DJ, et al: Inhibition of toll-like receptor 4 with eritoran attenuates myocardial ischemia-reperfusion injury. Circulation 114 (Suppl 1): S1270-S1274, 2006.

36. van der Pouw Kraan TC, Bernink FJ, Yildirim C, Koolwijk P, Baggen JM, Timmers L, Beek AM, Diamant M, Chen WJ, van Rossum AC, et al: Systemic toll-like receptor and interleukin-18 pathway activation in patients with acute ST elevation myocardial infarction. J Mol Cell Cardiol 67: 94-102, 2014.

37. Akira S and Takeda K: Toll-like receptor signaling. Nat Rev Immunol 4: 499-511, 2004.

38. Timmers L, van Keulen JK, Hoefer IE, Meijs MF, van Middelaar B, den Ouden K, van Echteld CJ, Pasterkamp G and de Kleijn DP: Targeted deletion of nuclear factor kappaB p50 enhances cardiac remodeling and dysfunction following myocardial infarction. Circ Res 104: 699-706, 2009.

39. Yin Q, Lin SC, Lamothe B, Lu M, Lo YC, Hura G, Zheng L, Rich RL, Campos AD, Myszka DG, et al: E2 interaction and dimerization in the crystal structure of TRAF6. Nat Struct Mol Biol 16: 658-666, 2009. 